\title{
Evaluation of Boundary-Enhancement Additives for Perfluoropolyethers
}

Bradley A. Shogrin

Case Western Reserve University

Cleveland, Ohio

William R. Jones, Jr.

Lewis Research Center

Cleveland, Ohio

Pilar Herrera-Fierro

Ohio Aerospace Institute

Brook Park, Ohio

Tzuhn-Yuan Lin and Hajimu Kawa

Exfluor Research Corporation

Round Rock, Texas

Prepared for the

1997 Tribology Conference

cosponsored by the Society of Tribologists and Lubrication Engineers and the American Society of Mechanical Engineers

London, United Kingdom, September 8-12, 1997

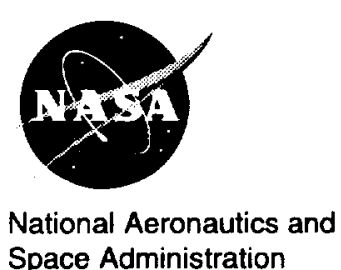

Space Administration 



\title{
Evaluation of Boundary-Enhancement Additives \\ for Perfluoropolyethers
}

\author{
Bradley A. Shogrin \\ Case Western Reserve University \\ Cleveland, OH 44106 \\ William R. Jones, Jr. \\ NASA Lewis Research Center \\ Cleveland, $\mathrm{OH} 44135$ \\ Pilar Herrera-Fierro \\ Ohio Aerospace Institute \\ Brookpark, OH 44142 \\ Tzuhn-Yuan Lin and Hajimu Kawa \\ Exfluor Research Corp. \\ Round Rock, TX 78664
}

\begin{abstract}
Six additives were synthesized and evaluated as boundary lubrication enhancers for perfluoropolyethers. These additives included a phosphonate, a thiophosphonate, a $\beta$ diketone, a benzothiazole, an amide and a sulfite. These additives were evaluated in a vacuum four-ball apparatus, at a one weight percent concentration in a perfluoropolyether based on hexafluoropropene oxide. Tests were performed in vacuum ( $\left.<5.0 \times 10^{-6} \mathrm{Torr}\right)$, at room temperature $\left(\sim 23^{\circ} \mathrm{C}\right)$, at an initial Hertzian stress of $3.5 \mathrm{GPa}(200 \mathrm{~N} \mathrm{load})$, and a sliding velocity of $28.8 \mathrm{~mm} / \mathrm{sec}(100 \mathrm{rpm})$. Infrared (IR) and Raman spectroscopies were used to analyze the $440 \mathrm{C}$ specimens after testing. Wear rates for each formulation were determined from the slope of wear volume as a function of sliding distance. All additives yielded reductions in mean wear rates of at least 55 percent, with the exception of the benzothiazole which had no effect. Two of the additives, an amide and a sulfite, reduced the mean wear rate by at least 80 percent. IR and Raman analysis indicated the severity of wear can be correlated to the amount of surface fluorinated polymeric acid species $\left(\mathrm{R}_{\mathrm{f}} \mathrm{COOH}\right)$ and amorphous carbon, in and around the wear scar.
\end{abstract}

Keywords: Perfluoropolyethers, boundary lubrication, additives 


\section{INTRODUCTION}

Perfluoropolyethers (PFPE) are widely employed as lubricants for space applications because of their excellent thermal (1) and chemical stability (2) and are particularly effective in the elastohydrodynamic regime (3). However, when used as a boundary lubricant, PFPE performance is more variable and less predictable (4), (5). The most significant problem encountered when using PFPE's in the boundary lubrication regime is the unavailability of soluble additives. This results from the fact that the vast additive technology developed for hydrocarbon and ester based lubricants cannot be applied to PFPE's because of their inherent insolubility. Soluble phosphorus based additives (phosphines and phosphatriazines) have been developed for anti-corrosion and anti-degradation $(6),(7)$ but these have little or no boundary lubrication activity $(8),(9)$.

Masuko et al. (10) studied a series of PFPE derivatives (acids, alcohols, and phosphate esters) in a linear PFPE basestock produced by the polymerization of tetrafluorooxetane followed by direct fluorination (D fluid)(11). A vacuum four-ball apparatus was used. These additives yielded some antiwear activity, with the PFPE terminated acid being the most effective. Sharma et al. (12) reported anti-wear activity for an additive (structure not disclosed) in a linear PFPE based on tetrafluoroethylene ( $Z$ fluid)(13). Later, this additive was identified as a PFPE alcohol (8). Reference (8) also reported antiwear behavior for a PFPE ketone. Antiwear activity has also been reported (14) for two other PFPE derivatives: a polar amine salt and a phosphorus containing end group. Nakayama et al. (15) reported wear behavior in vacuum and various atmospheres for two PFPE additives: a carboxylic acid and an aminophenylsulfone. The carboxylic acid additive reduced wear in vacuum, while the sulfone accelerated wear under the same conditions.

Recently, NASA has developed a four-ball apparatus and a test protocol for the evaluation of liquid lubricants and greases for space applications (10). This device can operate as a vacuum tribometer or with a series of different atmospheres. A series of mono and diaryl esters were evaluated as antiwear additives in a $Z$ fluid using a dry air atmosphere (17). Under these conditions, two monoesters yielded wear reductions of 60 and $35 \%$. One diester had no effect, while two other diesters were actually prowear.

Therefore, the objective of this work was to evaluate a series of newly synthesized soluble additives for their antiwear activity in a poly (hexafluoropropene oxide) basestock ( $\mathrm{K}$ fluid). Types of additives included a phosphonate, a thiophosphonate, a $\beta$-diketone, a benzothiazole, an amide and a sulfite. Additives were evaluated at a one weight percent concentration by measuring steady state wear rates and coefficients of friction using the four ball apparatus. Test conditions included: vacuum $\left(<5.0 \times 10^{-6} \mathrm{Torr}\right), 200 \mathrm{~N}$ load, a speed of $100 \mathrm{rpm}$, room temperature $\left(\sim 23^{\circ} \mathrm{C}\right), 440 \mathrm{C}$ stainless steel bearing balls and a total test duration of approximately four hours. 


\section{EXPERIMENTAL}

\section{Lubricant Basestock}

A branched PFPE basestock, poly (hexafluoropropene oxide) fluid, was chosen for the evaluations. This is a commercially available fluid made by $\mathrm{CsF}$ catalyzed polymerization of hexafluoropropene oxide yielding a series of branched polymers ( $\mathrm{K}$ fluids). These lubricants have been used extensively in various space applications, such as filter wheels and scanning mechanisms (5), (18). Physical properties for the fluid used in this study appear in Table 1.

\section{Lubricant Additives}

Six different additives with various functional groups were synthesized for this study. These included: a phosphonate, a thiophosphonate, a $\beta$-diketone, a benzothiazole, an amide and a sulfite. All had long PFPE groups for solubilization, and high molecular weights to maintain low vapor pressures. Structures for these additives appear in Table 2. Each additive was evaluated at a one weight percent concentration in the poly (hexafluoropropene oxide) basestock.

\section{Tribometer}

A four-ball tribometer (Figure 1), operating in the boundary lubrication mode, was used to measure steady state wear rates and friction coefficients for each lubricant formulation and the additive-free basestock. Specimen configuration (Figure 2) is the same as the conventional four-ball apparatus, except for the use of $9.5 \mathrm{~mm}(3 / 8 \mathrm{in}$.) diameter precision bearing balls (grade 10). A complete description of this device appears in reference $(10)$.

\section{Procedure Prior to Testing}

Prior to testing, the balls and lubricant cup were ultrasonically cleaned in hexane, acetone and finally methanol for ten minutes each. The lubricant cup was then ultrasonically cleaned for ten minutes in two consecutive trifluorotrichloroethane baths. The balls were then blown dry with nitrogen, followed by UV/ozone treatment (19) for 15 minutes. Within 5 minutes of UV/ozone treatment, three of the balls were placed into the lubricant cup and covered with the test lubricant, and the remaining ball was placed into the nitrogen-backfilled tribometer and used as the rotating ball. After the balls were secured in the lubricant cup, it was evacuated in a bell jar for one hour at 0.01 Torr to remove dissolved gases. The cup was then placed into position inside the tribometer and the chamber evacuated. 


\section{Test Procedure}

After reaching the desired base pressure $\left(<5.0 \times 10^{-6}\right.$ Torr), the stage was pneumatically loaded against the rotating ball and rotation initiated. The load was $200 \mathrm{~N}$ $\pm 5 \%$, giving an initial Hertzian stress of $3.5 \mathrm{GPa}$. The sliding speed was $28.8 \mathrm{~mm} / \mathrm{sec}$ (ball rotating speed of $100 \mathrm{rpm}$ ).

Friction torque was recorded continuously by using a Hall-effect position sensor. The Hall-effect position sensor provides an indirect measurement of torque by measuring the relative angular displacement of the lubricant cup which is attached to a flex pivot.

Wear was determined by measuring wear scar diameters on the three stationary balls using an optical microscope. The average wear scar diameter was used to calculate a wear volume. A sample stage on the microscope was so designed that the wear scars could be measured without disassembling the balls from the cup. The experiment was then continued using the same set of balls. Typically, the four hour test was interrupted three times (on each hour) for wear scar measurements. After the test was completed, final wear scar measurements were taken. A wear rate $\left(\mathrm{mm}^{3} / \mathrm{mm}\right)$ was calculated from the slope of the straight line obtained by plotting wear volume as a function of sliding distance. An example of data for the PFPE base fluid using the aforementioned conditions is shown in Figure 3. Each of the four data points represents the average of the three balls for one wear scar measurement. The wear rate for this particular test was calculated to be $0.690 \times 10^{-9} \mathrm{~mm}^{3} / \mathrm{mm}$.

A total of eight tests were performed using the additive-free base fluid. Each additive formulation was run either three or four times (limited by the amount of available additive). After each set of tests for either the base fluid or the additive formulation was completed, the lubricant cup was ultrasonically cleaned for ten minutes in two consecutive trifluorotrichloroethane baths.

\section{Lubricant Degradation Characterization}

The balls of one test, both for the base fluid and each additive formulation, were analyzed using a FT infrared microscope ( $\mu$-FTIR) and a Raman microscope ( $\mu$-Raman). The FTIR analysis was performed in the reflectance mode using a $32 \mathrm{X}$ infrared objective and a $100 \mu \mathrm{m}$ diameter spot size. The spectral resolution and acquisition time were $8 \mathrm{~cm}^{-1}$, and 400 seconds, respectively. A gold coated glass slide was used to acquire a background spectrum.

Raman analysis was performed using a $15 \mathrm{~mW}$ Ar laser (5414.5 nm wavelength), with an analyzing spot diameter of $2 \mu \mathrm{m}$, and a $50 \mathrm{X}$ objective. The acquisition time was 50 seconds and the spectral range was 150 to $3200 \mathrm{~cm}^{-1}$. The instrument was aligned to both the type-2A diamond line at $1331.2 \mathrm{~cm}^{-1}$, and $\mathrm{Si}(111)$ at $520.8 \mathrm{~cm}^{-1}$. Care was 
taken when exposing the organic films to the laser beam since damage can occur that results in similar degradation to that produced by a tribological process.

Efforts were made to only compare spectra taken from areas of the scar with similar characteristics. Analysis of each ball was performed at several locations, both on and off the wear scar. The balls of each test were analyzed under two different conditions with the FTIR and Raman, the first, with the bulk lubricant on the ball, and, the second, after being rinsed with a fluorinated solvent $(\mathrm{X}-100)$ that removed the excess lubricant. Generally, many features not noticeable before rinsing, were apparent around the scar after rinsing.

\section{RESULTS}

Wear

The wear results are tabulated in the first three columns of Table 3 . The numbers appearing within parentheses in the standard deviation column are the number of tests performed using that formulation. The wear data of table 3 is shown graphically in Figure 4. The bar graphs represent the mean wear rates of the specified formulations, whereas the error bars signify one standard deviation.

The tabulated results in table 3 indicate that the additive formulations yielded reductions in the mean wear rates of at least 55 percent compared to the base stock's value, with the exception of the benzothiazole which had no effect. The benzothiazole's mean wear rate improvement of 5 percent is well within the standard deviation, as seen in figure 4 . The $\beta$-diketone additive reduced the mean wear rate 70 percent. The amide and the sulfite were the most active, reducing the mean wear rate by 85 percent and 80 percent, respectively.

\section{Friction}

The friction results are tabulated in the last column of Table 3. The mean friction coefficient appears outside the parentheses, whereas the ranges are contained within the parentheses. These values were taken from the compilation of all the tests. These data are shown graphically in Figure 5. The bar graphs represent the mean friction coefficient, whereas the error bars signify the minimum and maximum friction coefficient for each formulation. Each of the mean friction coefficients are $\approx 0.13$, and have ranges that overlap one another. Therefore, it is concluded that the various additives did not have an effect on the wear couple's friction coefficient.

\section{DISCUSSION}

Under boundary lubrication conditions, PFPE base fluids normally operate in the corrosive wear regime. In this lubrication regime, PFPE's decompose producing a series 
of corrosive products, which, in turn, react with existing surface oxides, producing metal fluorides (4),(20). These fluorides provide lubrication protection to the contacting surfaces, reducing friction and wear $(20)$. Unfortunately, these fluorides also attack and further decompose the lubricant, producing more reactive products. Surface fluorides are constantly removed from the contact region, resulting in high wear of the substrate (i.e. corrosive wear). Therefore, a PFPE lubricated couple, operating in the boundary regime, relies upon the wear process for it's tribological protection.

In contrast, conventional unformulated hydrocarbon and ester based lubricants are relatively unreactive with the wear couple's surface and operate in the adhesive wear regime in boundary contacts. Typically, these fluids' commercial versions are fortified with reactive extreme pressure and/or anti-wear additives to encourage the formation of surface films. The resulting surface films reduce wear and friction and increase load capacity. Thus, these fluids' protection does not necessarily depend upon the decomposition of the basestock, but rather, a formation of protective surface films whose existence and effectiveness depends upon the type and concentration of additives.

Since conventional hydrocarbons and PFPE's undergo fundamentally different wear mechanisms in boundary lubricated contacts, additives that perform well in one may not necessarily perform well in the other. Additives used in hydrocarbon based lubricants are not soluble in fluorinated lubricants. Methods to render them soluble sometimes results in loss of additive function. Since PFPE's are already operating in a corrosive wear mode, an effective additive must reduce this wear rate to an acceptable level. This can be accomplished by incorporating an additive which poisons enough catalytic sites to reduce reaction rates. An additive may also be effective reacting with the substrate to form secondary compounds. The formation of these compounds would have a two fold effect; 1) these compounds may provide additional wear protection, and 2) because they react with the substrate, they occupy the metal-sites, which indirectly reduces the formation of the PFPE-degrading metal fluorides.

\section{ß-Diketone Additive}

$\beta$-diketone compounds are not normally used as additives for conventional hydrocarbon oils because they are considered surface site blockers, and not protective film providers. $\beta$-diketones are well known complexing agents for polyvalent metals in their enolate form (21). It was thought that, as a PFPE additive, $\beta$-diketone might effectively block catalytic sites which would reduce reaction rates. In this study, the $\beta$ diketone formulation proved effective in enhancing the performance of the base stock.

\section{Phosphorous Additives}

Phosphorous based additives are the most common anti-wear additives formulated for conventional lubricants. It is thought that these additives adsorb onto the surface, 
degrade under the contact stresses to form species which react with the substrate to form organo/inorgano phosphorous compounds (22). Thus, a functioning phosphorous additive in a PFPE would, 1) block catalytic sites, and 2) reduce the concentration of the PFPE-degrading metal-fluorides indirectly by providing competition (via the formed surface species) for the lubricant molecules for the remaining active sites. In addition, the formed surface species and organo/inorgano phosphorous compounds could provide additional wear protection. Both the phosphonate and the thiophosphonate compounds were effective in enhancing the performance of the base stock.

\section{Sulfur Additives}

Sulfur, along with chlorine, based additives are the most common extreme pressure additives formulated for hydrocarbon oils. These additives function the same way as anti-wear additives, but are generally less reactive, requiring higher temperatures or loads to form protective films. Both the amide and sulfite formulations improved the wear performance of the base fluid, whereas, the benzothiazole was ineffective.

\section{IR and Raman Observations}

The additives were not detectable by IR or Raman in the additive formulations because of their low concentrations. However, other distinguishable features were apparent. Figure 6 shows a typical wear scar before and after solvent rinsing. After the excess lubricant was removed by rinsing, features previously hidden were observed. Of interest is the brownish material around, and on the wear scar, which began to accumulate after initiation of testing. The relative amount of this brownish material correlated to the severity of wear. This brownish material has been observed before, and has been described as a "friction polymer" (23). This friction polymer is not soluble in fluorinated solvents, is strongly attached to the metal surface, and has several unique chemical features, absent from the unused PFPE. IR and Raman analysis of this friction polymer has indicated that it contains both polymeric fluorinated acid species $\left(\mathrm{R}_{\mathrm{f}} \mathrm{COOH}\right)$, and amorphous carbon (23). The formation of this friction polymer is seen as a measure of PFPE degradation.

Figure 7 compares the IR spectra of the friction polymer region before and after solvent rinsing ( $b$ and $a$, respectively) for the benzothiazole-formulated test, to that of unused PFPE on a 440C surface (c). Both the unused PFPE spectra, and the spectra prior to solvent rinsing contain the characteristic C-F vibrations of this particular PFPE at 990 $\mathrm{cm}^{-1}$, and in the region between 1127 and $1310 \mathrm{~cm}^{-1}$. These peaks have nearly disappeared from the spectra of the rinsed surface, indicating that the majority of the PFPE has been removed. The absence of the C-F peaks in this spectra has amplified the signals of other notable peaks. In particular, the peaks at $1436,1669 \mathrm{~cm}^{-1}$, and the broad band between $3000-3600 \mathrm{~cm}^{-1}$. The broad band $\left(3000-3600 \mathrm{~cm}^{-1}\right)$ has been assigned to hydrogen bonded hydroxyl groups, whereas, the other two bands have been assigned to carboxylic acid species (23). These peaks also appear in the spectra of the "before- 
rinsed" surface, but are not as distinguishable due to the low concentration of these species, and the shadowing-effect by the signal from the base lubricant.

The relative intensities of the above mentioned peaks were found to directly correlate with the amount of wear. Figure 8 shows the typical IR spectra of the friction polymer region after solvent rinsing for each formulated test, and the additive-free test. The amount of polymer present is directly related to the relative intensities of it's peaks. The legend indicates the specific wear rates for each test represented, as well as the mean wear rate for that additive's set of tests (from Table 3). For example, the spectra for the $\beta$-diketone additive was taken from a ball from a test that had a wear rate of $2.14 \times 10^{-10}$ $\mathrm{mm}^{3} / \mathrm{mm}$. Whereas, the mean wear rate for all the $\beta$-diketone tests was $1.88 \times 10^{-10}$ $\mathrm{mm}^{3} / \mathrm{mm}$. The additives can be ranked according to the relative strengths of these peaks (relative amount of polymer present) as follows: benzothiazole $>$ base fluid $>$ thiophosphonate $>\beta$-diketone $>$ sulfite $>$ phosphonate $>$ amide. Therefore, it can generally be said that the higher the wear rate, the more polymer is present.

Typical Raman spectra of the region from 1000 to $1900 \mathrm{~cm}^{-1}$ for each formulated test (except amide), and the base fluid test are shown in Figure 9. These spectra were taken from within the scar after solvent rinsing, where the polymeric material was not as dense to prevent signal saturation. Similar to the IR spectral peaks of $1436,1669 \mathrm{~cm}^{-1}$, and $3000-3600 \mathrm{~cm}^{-1}$, the Raman spectral peaks 1364 and $1604 \mathrm{~cm}^{-1}$ represent products of tribo-induced, chemically degraded poly (hexafluoropropene oxide) PFPE (23). The Raman peak at $1364 \mathrm{~cm}^{-1}$ can be assigned to the so called " $D$ " band, and serves as a direct measure of the order, or disorder, of this tribologically created structure. The broad band at $1604 \mathrm{~cm}^{-1}$ is the " $\mathrm{G}$ " peak found in highly oriented pyrolytic graphite at $1576 \mathrm{~cm}^{-1}$. This peak has been previously assigned to scattering by graphitic optic zone center phonons (24). This band shifts, and broadens, primarily as a result of the change from $C$ $\mathrm{sp}^{3}$ to $\mathrm{C} \mathrm{sp}{ }^{2}$ bonding (24). The occurrence of these two Raman peaks strongly suggests $\mathrm{C}=\mathrm{C} \mathrm{sp}^{2}$ type bonding, and therefore, the presence of a cross-linked-induced $\mathrm{C}-\mathrm{C}$ network. Cross linking has long been thought of as being the critical, and final, step in the degradation process of perfluorinated materials (25).

The "G" and "D" peaks are absent in the spectra of unused PFPE on 440C steel, and are absent in the $\beta$-diketone, phosphonate, and thiophosphonate spectra. These peaks are more profound in the additive runs containing benzothiazole, sulfite, and the additivefree run. Theoretically, the relative heights of these peaks should correspond to the amount of wear, as did the subject spectral peaks of the IR data. In fact, given a larger analyzing area, it is suspected that a better correlation between the relative absorbances of the 1364 and $1604 \mathrm{~cm}^{-1}$ Raman peaks and wear could be attained. It is thought that the small spot size used to obtain these data (diameter of $2 \mu \mathrm{m}$ ) prevented sufficient averaging over the analyzed area. This, coupled with the inherent nonuniform nature of the wear scar produced wide variations in spectral absorbances of these peaks when analyzing areas in proximity to one another on the same wear scar. This was not a significant problem with the IR analysis, as it utilized the larger analyzing diameter of 
$100 \mu \mathrm{m}$. This allowed for averaging over a larger area, and a better representation of the features that are present.

\section{SUMMARY OF RESULTS}

1) Five different additives with various functional groups: a phosphonate, a thiophosphonate, a $\beta$-diketone, an amide and a sulfite, all exhibited antiwear activity in a poly (hexafluoropropene oxide) basestock at one weight percent concentration.

2) The amide and the sulfite additive at one weight percent were the most effective, reducing the mean wear rate, from that of the additive-free base stock, by 85 percent and 80 percent, respectively.

3) One additive with a benzothiazole functional group showed no antiwear activity at one weight percent concentration.

4) The wear couples mean friction coefficient was not affected by any of the six additive formulations tested.

\section{CONCLUSIONS}

1) Soluble additives can be developed that reduce wear in vacuum for poly (hexafluoropropene oxide) PFPE fluids.

2) The severity of wear can be correlated to the amount of fluorinated polymeric acid species $\left(\mathrm{R}_{\mathrm{f}} \mathrm{COOH}\right)$, and the amount of amorphous carbon in and around the wear scar. 


\section{REFERENCES}

(1) Helmick., L.S. and Jones, W.R., Jr., "Determination of the Thermal Stability of Perfluoropolyalkyl Ethers by Tensimetry," Lubr. Eng., 50, 6, p 449, (1994).

(2) Del Pesco, T.W., "Perfluoroalkylpolyethers," Chapter 6 in Synthetic Lubricants and High-Performance Functional Fluids, ed. R. L. Shubkin, Marcel Dekker, New York, 145172, (1993).

(3) Jones, W.R., Jr., "Properties of Perfluoropolyethers for Space Applications," Trib. Trans., 38, 3, p 557, (1995).

(4) Carré, D.J., "Perfluoropolyalkylether Oil Degradation: Inference of $\mathrm{FeF}_{3}$ Formation on Steel Surfaces Under Boundary Conditions," ASLE Trans. 29, 2, p 121, (1986).

(5) Conley, P.L. and Bohner, J.J., "Experience with Synthetic Fluorinated Fluid Lubricants," 24th Aerospace Mech. Symp., NASA CP 3062, p 213 (1990).

(6) Tamborski, C., Snyder, C.E., Jr., and Christian, J. B., "Perfluoroalkylether Substituted Phenyl Phosphines," U. S. patent 4,454,349 (1984).

(7) Kratzer, R.H., Paciorek, K.J.L., Kaufman, J., and Ito, T.I., "Phospha-s-triazines. I. Synthesis and Properties of Mono (diarylphospha)-s-triazines," J. Fluorine Chem. 10, p 231, (1977).

(8) Gschwender, L.J., Snyder, C.E., Jr., and Fultz, G.W., "Soluble Additives for Perfluoropolyalkylether Liquid Lubricants," Lubr. Eng., 49, 9, p 702, (1993).

(9) Jones, W.R., Jr., Ajayi, O.O., Goodell, A.J., Wedeven, L.D., Devine, E., and Predmore, R.E., "Enhancement of Perfluoropolyether Boundary Lubrication Performance. I. Preliminary Results," NASA TM 106937, Lewis Research Center, Cleveland, $\mathrm{OH},(1995)$.

(10) Masuko, M., Fujinami, I., and Okabe, H., "Lubrication Performance of Perfluoropolyalkylethers Under High Vacuum," Wear, 159, p 249, (1992).

(I1) Ohsaka, Y., "Recent Advances in Synthetic Lubricating Oils, (8) Perfluoropolyethers," Petrotech (Tokyo), 8, 9, p 840, (1985).

(12) Sharma, S.K., Gschwender, L.J., and Snyder, C.E., Jr., "Development of a Soluble Lubricity Additive for Perfluoropolyalkylether Fluids," J. Syn. Lub., 7, p 15, (1990).

(13) Sianesi, D., Pasetti, A., Fontanelli, R., and Bernardi, G.C., "Perfluoropolyethers by Photooxidation of Fluoroolefins," Chim. Ind., (Milan), 55, p 208, (1973). 
(14) Srinivasan. P., Corti, C., Montagna, L., and Savelli, P., "Soluble Additives for Perfluorinated Lubricants," J. Syn. Lub., 10, 2, p 143, (1993).

(15) Nakayama, K., Dekura, T., and Kobayashi, T., "Effect of Additives on Friction, Wear, and Iron Fluoride Formation under Perfluoropolyether Fluid Lubrication in Vacuum and Various Atmospheres Containing Oxygen," Wear, 192, p 178, (1996).

(10) Masuko, M., Jones, W.R., Jr., Jansen, R., Ebihara, B., Pepper, S.V., and Helmick, L. "A Vacuum Four-Ball Tribometer to Evaluate Liquid Lubricants for Space Applications," Lubr. Eng., 5, 11, p 871, (1994).

(17) Williams, J.R., Feuchter, D.K., and Jones, W.R., Jr., "Development and Preliminary Evaluation of Aryl Ester Boundary Additives for Perfluoropolyethers,"NASA TM 106603, Lewis Research Center, Cleveland, OH, (1994).

(18) Morales, W., Jones, W.R., Jr., and Buckley, D.H., "Analysis of a Spacecraft Instrument Ball Bearing Assembly Lubricated by a Perfluoroalkylether," NASA TM 87260, Lewis Research Center, Cleveland, OH (1986).

(19) Vig, J.R., "UV/Ozone Cleaning of Surfaces," J. Vac. Sci. Technol. A, 3, 3, 1027 1034, (1985).

(20) Mori, S., and Morales, W., "Tribological Reactions of Perfluoroalkyl Polyether Oils with Stainless Steel Under Ultrahigh Vacuum Conditions at Room Temperature," Wear, 132, 111-121, (1989).

(21) Cotton, F.A. and Wilkinson, G., Advanced Inorganic Chemistry, J. Wiley \& Sons, Inc., New York, NY, P 186, (1966).

(22) Forbes, E.S., "Antiwear and Extreme Pressure Additives for Lubricants," Tribology, 145-152, (August 1970).

(23) Herrera-Fierro, P., Shogrin, B., Jones, W.R., Jr., "Spectroscopic Analysis of Perfluoropolyether Lubricant Degradation During Boundary Lubrication," NASA TM 107299 (Sept. 1996).

(24) Dillon, R.O., Wollam, J.A., and Katkanant, V., "Use of Raman Scattering to Investigate Disorder and Crystallite Formation in As-Deposited and Annealed Carbon Films," Phys. Rev. B., 29, 3482, (1984).

(25) Sugimoto, I., and Miyake, S., "High Lubrication Performance of Tribologically Oriented Fluoropolymer Molecules Analyzed by Polarized Infrared Microspectroscopy," J. App. Phys., 67, (9), 4083-4089, (1990). 
Table 1. Properties of the PFPE Basestock

\begin{tabular}{|c|c|}
\hline Average molecular weight & $6250 \mathrm{amu}$ \\
\hline $\begin{array}{r}\text { Vapor pressure at } 38^{\circ} \mathrm{C} \\
\text { at } 260^{\circ} \mathrm{C}\end{array}$ & $\begin{array}{l}8 \times 10^{-8} \text { Torr } \\
2 \times 10^{-3} \text { Torr }\end{array}$ \\
\hline $\begin{array}{r}\text { Kinematic viscosity at } 20^{\circ} \mathrm{C} \\
\text { at } 99^{\circ} \mathrm{C}\end{array}$ & $\begin{array}{r}800 \text { centistokes } \\
26 \text { centistokes }\end{array}$ \\
\hline $\begin{array}{r}\text { Density at } 24^{\circ} \mathrm{C} \\
\text { at } 204^{\circ} \mathrm{C}\end{array}$ & $\begin{array}{l}1.90 \mathrm{~g} / \mathrm{ml} \\
1.59 \mathrm{~g} / \mathrm{ml}\end{array}$ \\
\hline Surface tension at $25^{\circ} \mathrm{C}$ & 19 dynes/cm \\
\hline
\end{tabular}

Table 2. Additive Structures

\begin{tabular}{|c|c|}
\hline Name & Structure \\
\hline Phosphonate & $\mathrm{O}=\mathrm{P}\left(\mathrm{OCH}_{2} \mathrm{CF}_{2} \mathrm{CF}_{2} \mathrm{OCF}_{2} \mathrm{CF}_{2} \mathrm{OCF}_{2} \mathrm{CF}_{2} \mathrm{OCF}_{2} \mathrm{CF}_{2} \mathrm{OCF}_{2} \mathrm{CF}_{2} \mathrm{CF}_{2} \mathrm{CF}_{3}\right)_{3}$ \\
\hline Thiophosphonate & $\mathrm{S}=\mathrm{P}\left(\mathrm{OCH}_{2} \mathrm{CF}_{2} \mathrm{CF}_{2} \mathrm{OCF}_{2} \mathrm{CF}_{2} \mathrm{OCF}_{2} \mathrm{CF}_{2} \mathrm{OCF}_{2} \mathrm{CF}_{2} \mathrm{OCF}_{2} \mathrm{CF}_{2} \mathrm{CF}_{2} \mathrm{CF}_{3}\right)_{3}$ \\
\hline$\beta$-Diketone & $\mathrm{CF}_{3} \mathrm{CF}_{2} \mathrm{CF}_{2} \mathrm{CF}_{2} \mathrm{OCF}_{2} \mathrm{CF}_{2} \mathrm{OCF}_{2} \mathrm{CF}_{2} \mathrm{OCF}_{2} \mathrm{CF}_{2} \mathrm{OCF}_{2} \mathrm{CF}_{2} \mathrm{COCH}_{2} \mathrm{COCH}_{3}$ \\
\hline Benzothiazole & $\mathrm{CF}_{3} \mathrm{CF}_{2} \mathrm{CF}_{2} \mathrm{CF}_{2} \mathrm{CF}_{2} \mathrm{CF}_{2} \mathrm{OCF}_{2} \mathrm{CF}_{2} \mathrm{OCF}_{2} \mathrm{CF}_{2} \mathrm{OCF}_{2} \mathrm{CF}$ \\
\hline Amide & $\mathrm{CF}_{3} \mathrm{CF}_{2} \mathrm{CF}_{2} \mathrm{CF}_{2} \mathrm{CF}_{2} \mathrm{CF}_{2} \mathrm{OCF}_{2} \mathrm{CF}_{2} \mathrm{OCF}_{2} \mathrm{CF}_{2} \mathrm{OCF}_{2} \mathrm{CF}_{2} \mathrm{CONHCH}_{2} \mathrm{CH}_{2} \mathrm{SH}$ \\
\hline Sulfite & $\left(\mathrm{CF}_{3} \mathrm{CF}\left(\mathrm{CF}_{3}\right) \mathrm{CF}_{2} \mathrm{CF}_{2} \mathrm{CF}_{2} \mathrm{CF}\left(\mathrm{CF}_{3}\right) \mathrm{CF}_{2} \mathrm{CH}_{2} \mathrm{O}\right)_{2} \mathrm{~S}=\mathrm{O}$ \\
\hline
\end{tabular}


Table 3. Wear Rate and Friction Summary

\begin{tabular}{|l|l|l|l|l|}
\hline Name & $\begin{array}{l}\text { Mean Wear Rate } \\
\left(\times 10^{-10} \mathrm{~mm}^{3} / \mathrm{mm}\right)\end{array}$ & $\begin{array}{l}\text { Wear Rate Standard } \\
\text { Deviation (No. of } \\
\text { Tests) } \\
\left(\times 10^{-10} \mathrm{~mm}^{3} / \mathrm{mm}\right)\end{array}$ & $\begin{array}{l}\text { Mean Wear } \\
\text { Rate } \\
\text { Improvement }\end{array}$ & $\begin{array}{l}\text { Mean \& } \\
\text { (Range) of } \\
\text { Friction } \\
\text { Coefficient }\end{array}$ \\
\hline Base Stock & 6.34 & $3.01(8)$ & - & $0.13(0.10-0.21)$ \\
\hline Phosphonate & 2.16 & $1.41(3)$ & $65 \%$ & $0.14(0.10-0.19)$ \\
\hline Thiophosphonate & 2.92 & $1.59(3)$ & $55 \%$ & $0.13(0.11-0.14)$ \\
\hline$\beta$-Diketone & 1.88 & $0.23(4)$ & $70 \%$ & $0.12(0.10-0.14)$ \\
\hline Benzothiazole & 6.09 & $3.81(3)$ & $5 \%$ & $0.13(0.11-0.14)$ \\
\hline Amide & 1.01 & $0.42(4)$ & $85 \%$ & $0.12(0.09-0.13)$ \\
\hline Sulfite & 1.20 & $0.15(3)$ & $80 \%$ & $0.13(0.12-0.13)$ \\
\hline
\end{tabular}




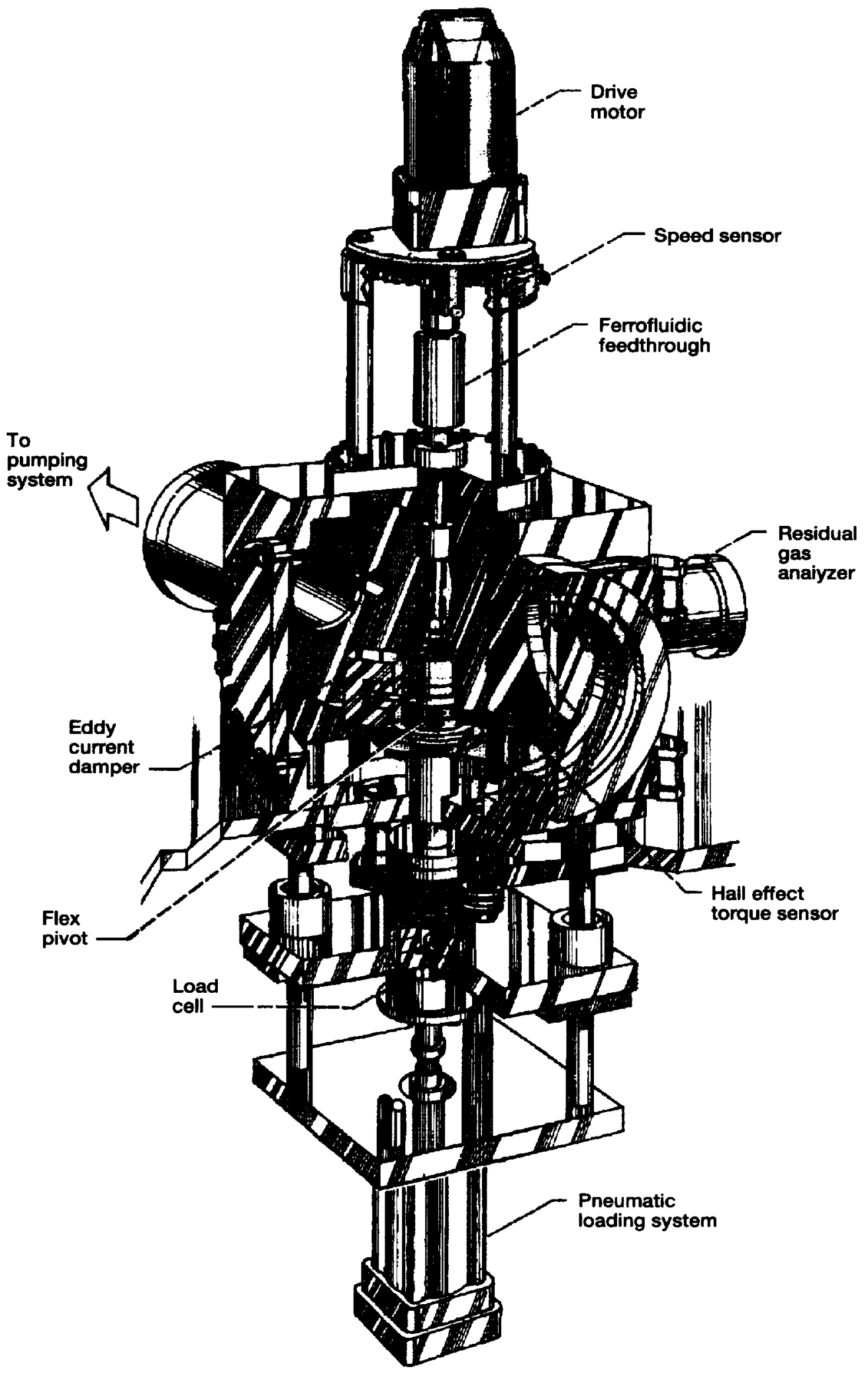

Figure 1.-Vacuum four-ball tribometer. 


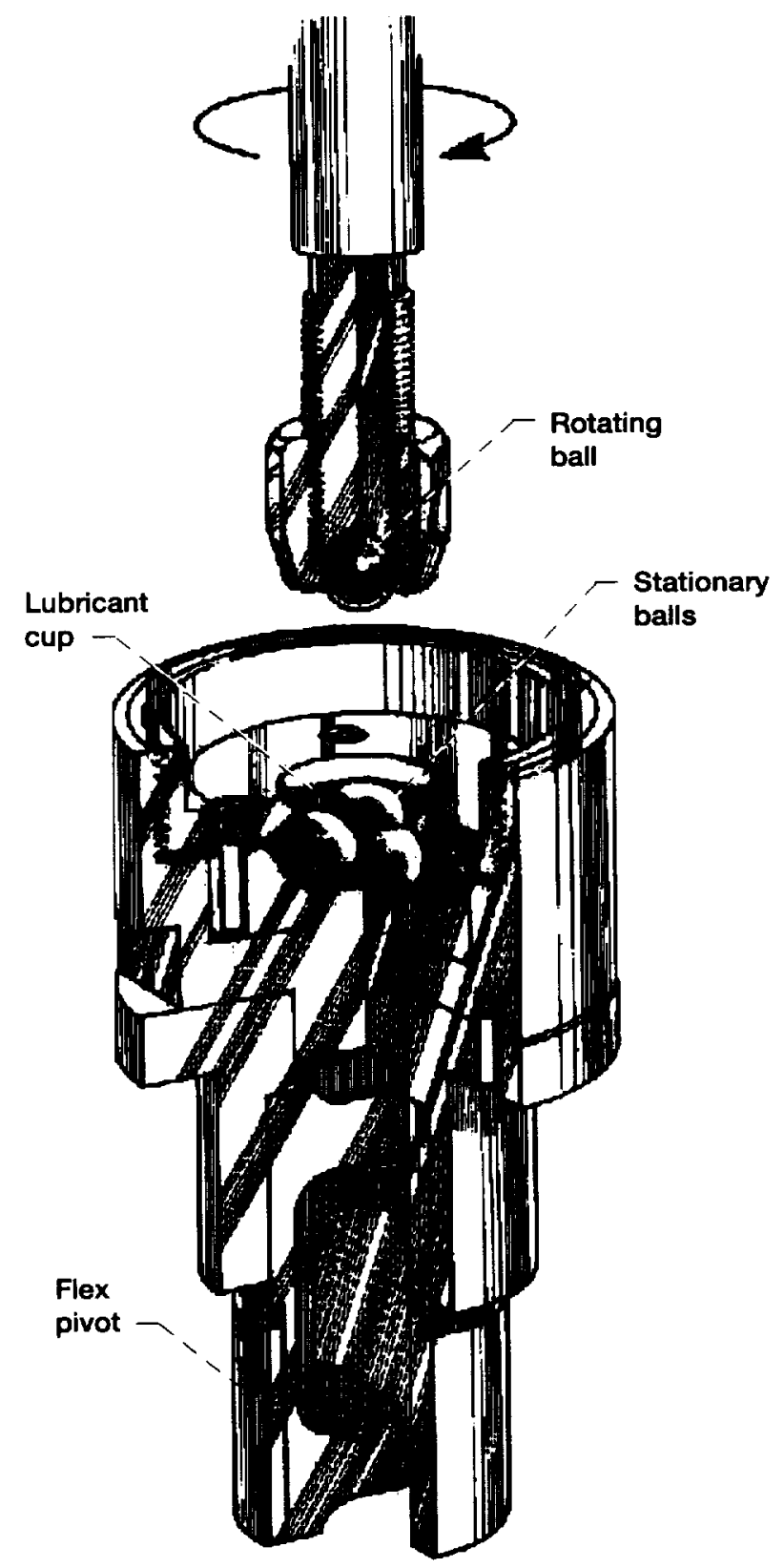

Figure 2.-Test specimen configuration. 


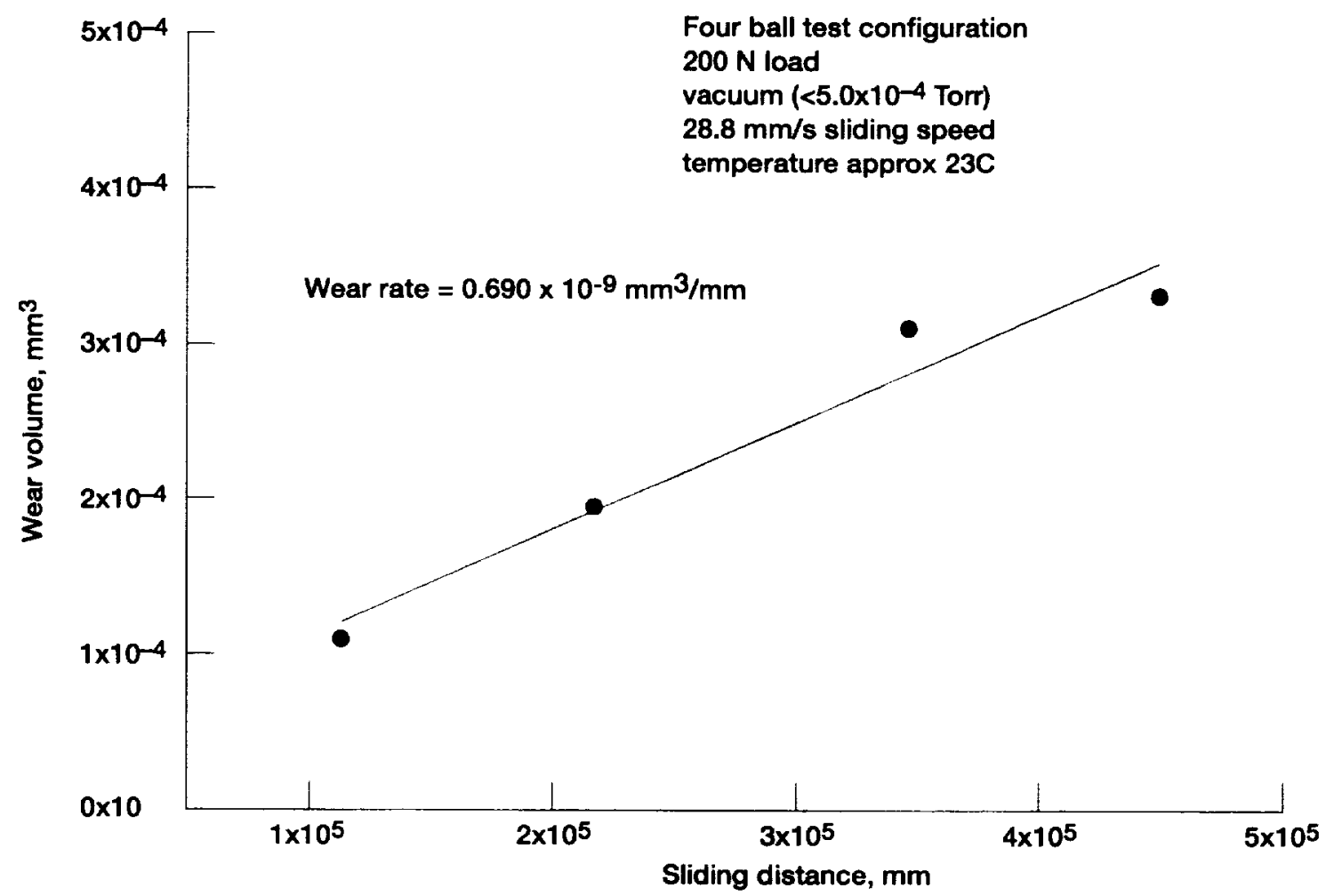

Figure 3.-Wear volume as a function of sliding distance for the unformulated lubricant.

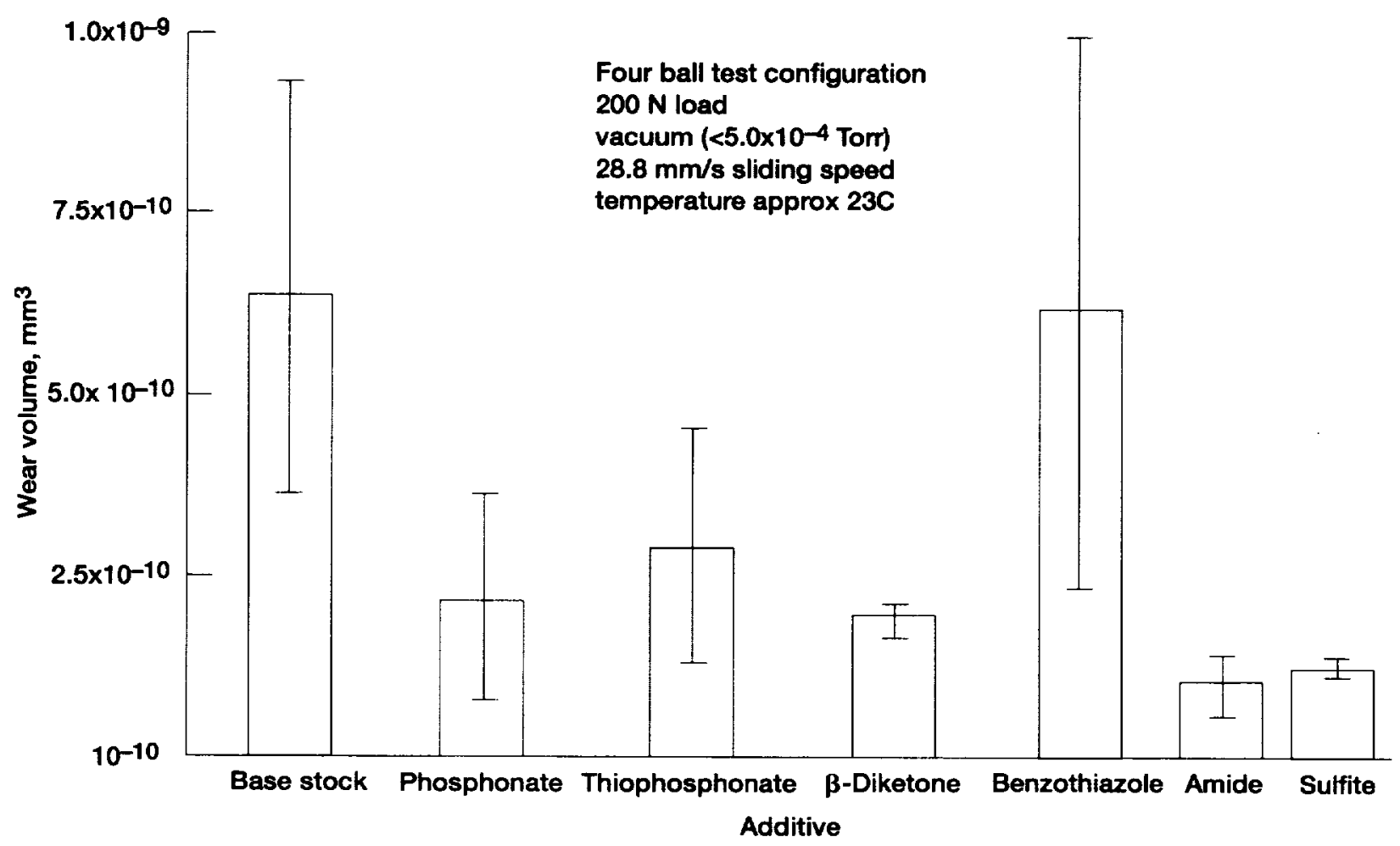

Figure 4.-Mean wear rates of the formulated and unformulated tests. Error bars represent one standard deviation. 


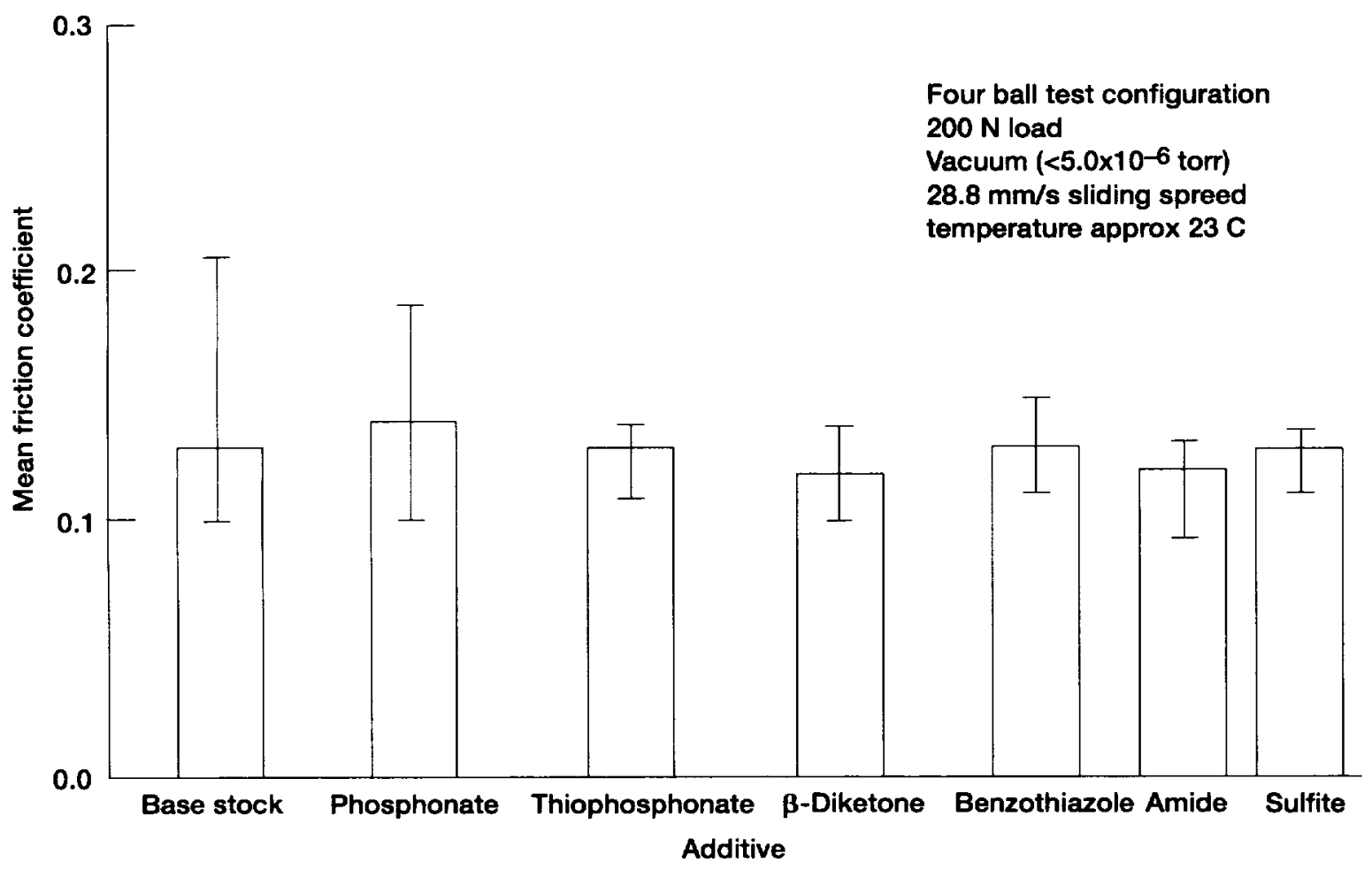

Figure 5.-Mean friction coefficients of the formulated and unformulated tests. Error bars represent mininum and maximum.
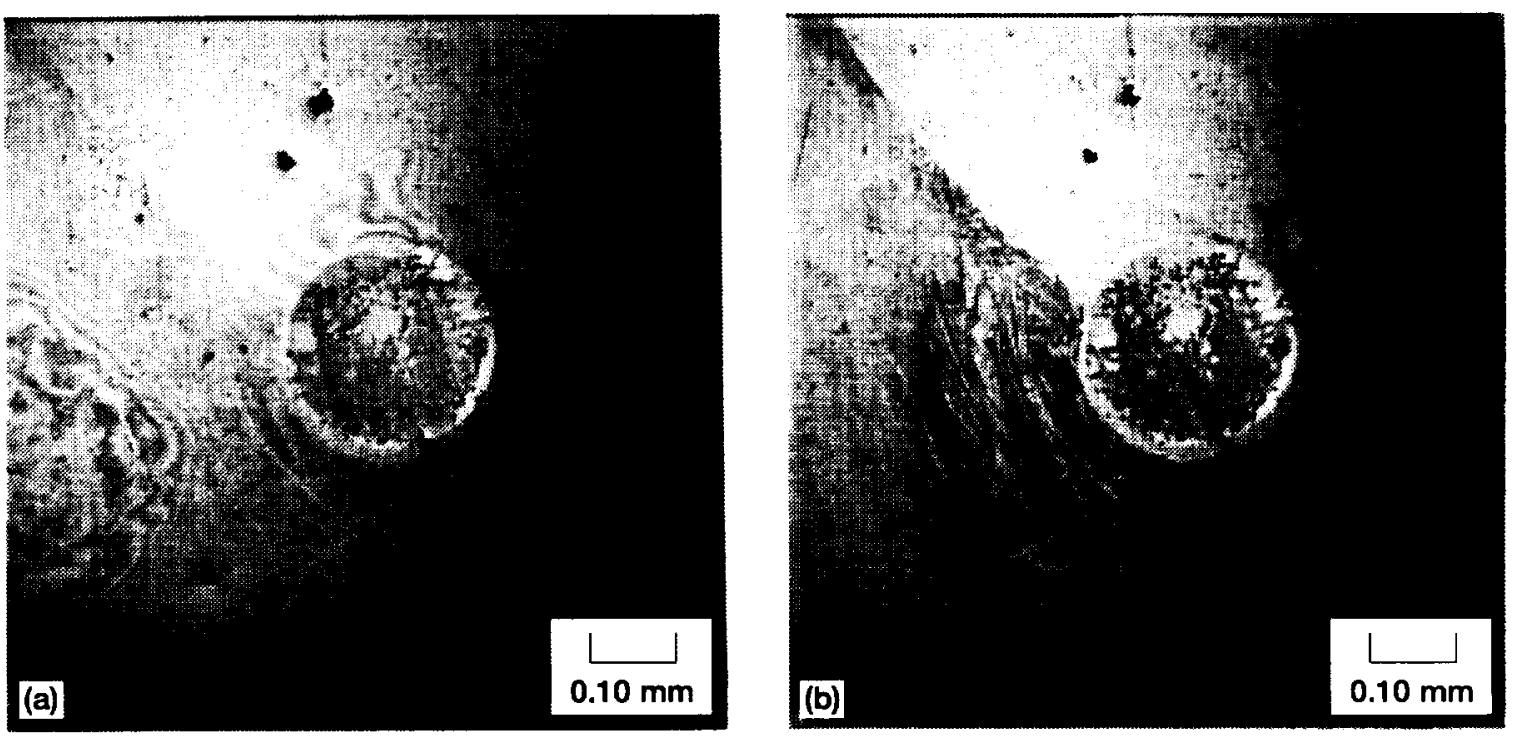

Figure 6.-Typical wear scar before (a) and after (b) solvent rinsing. 


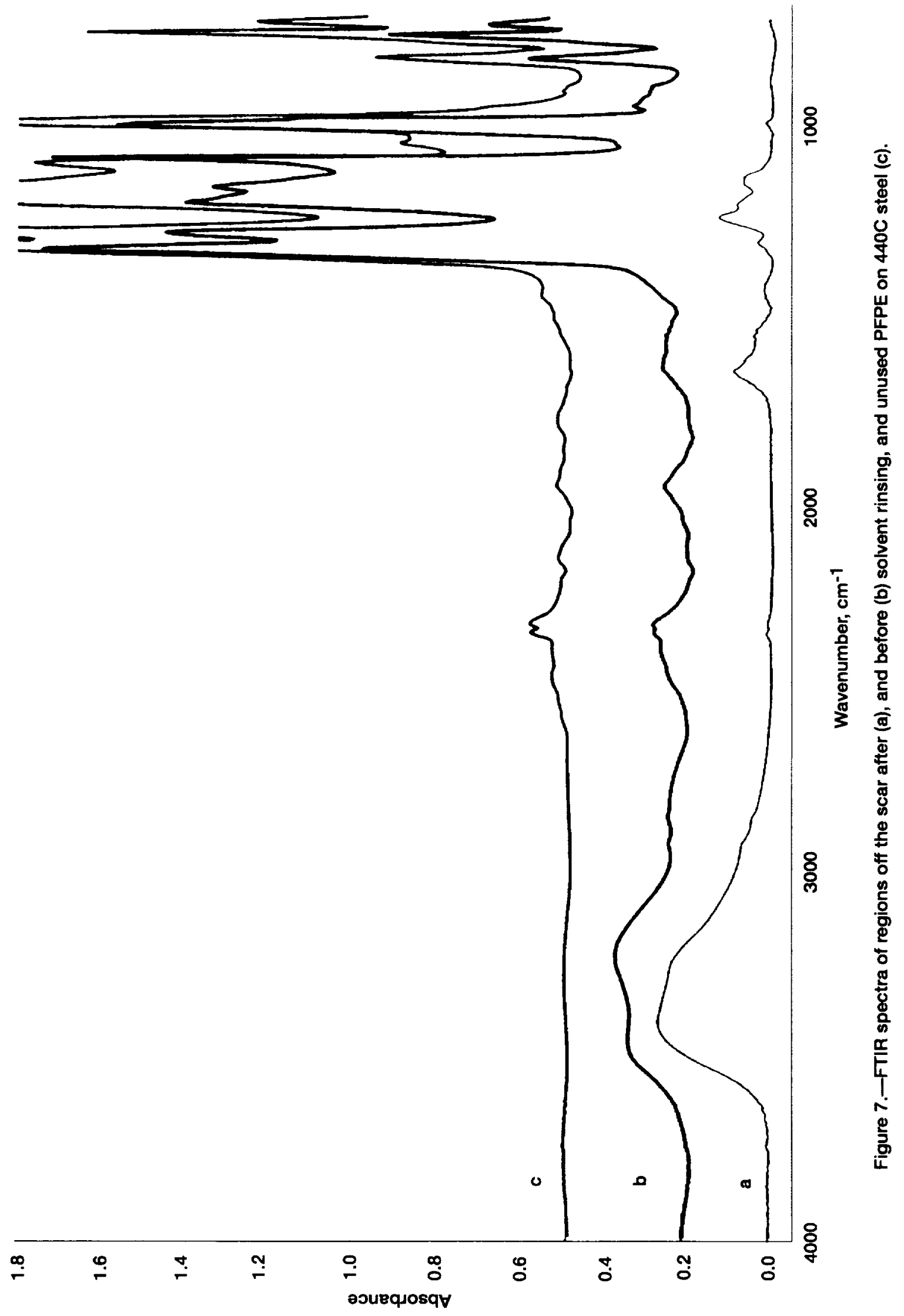




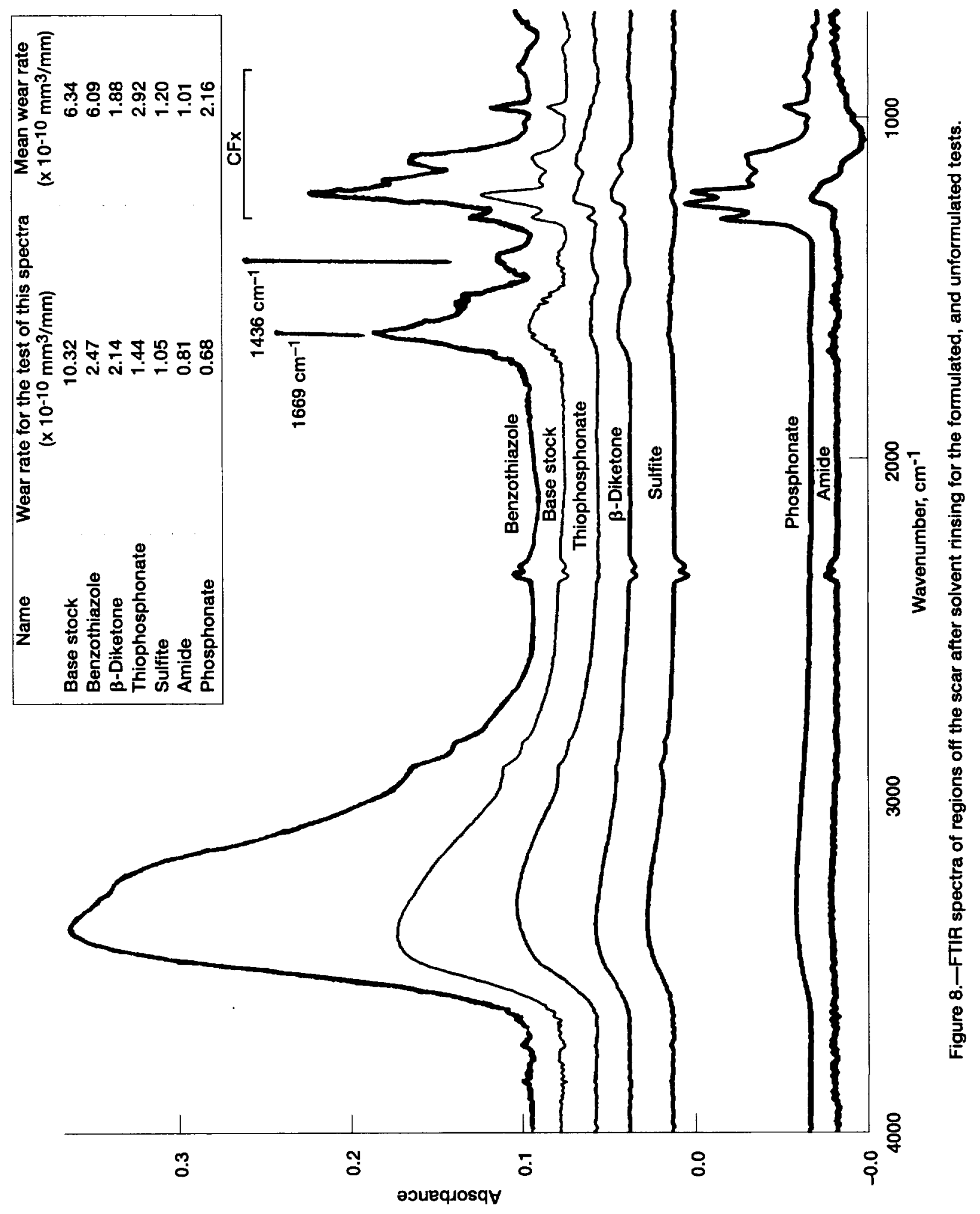




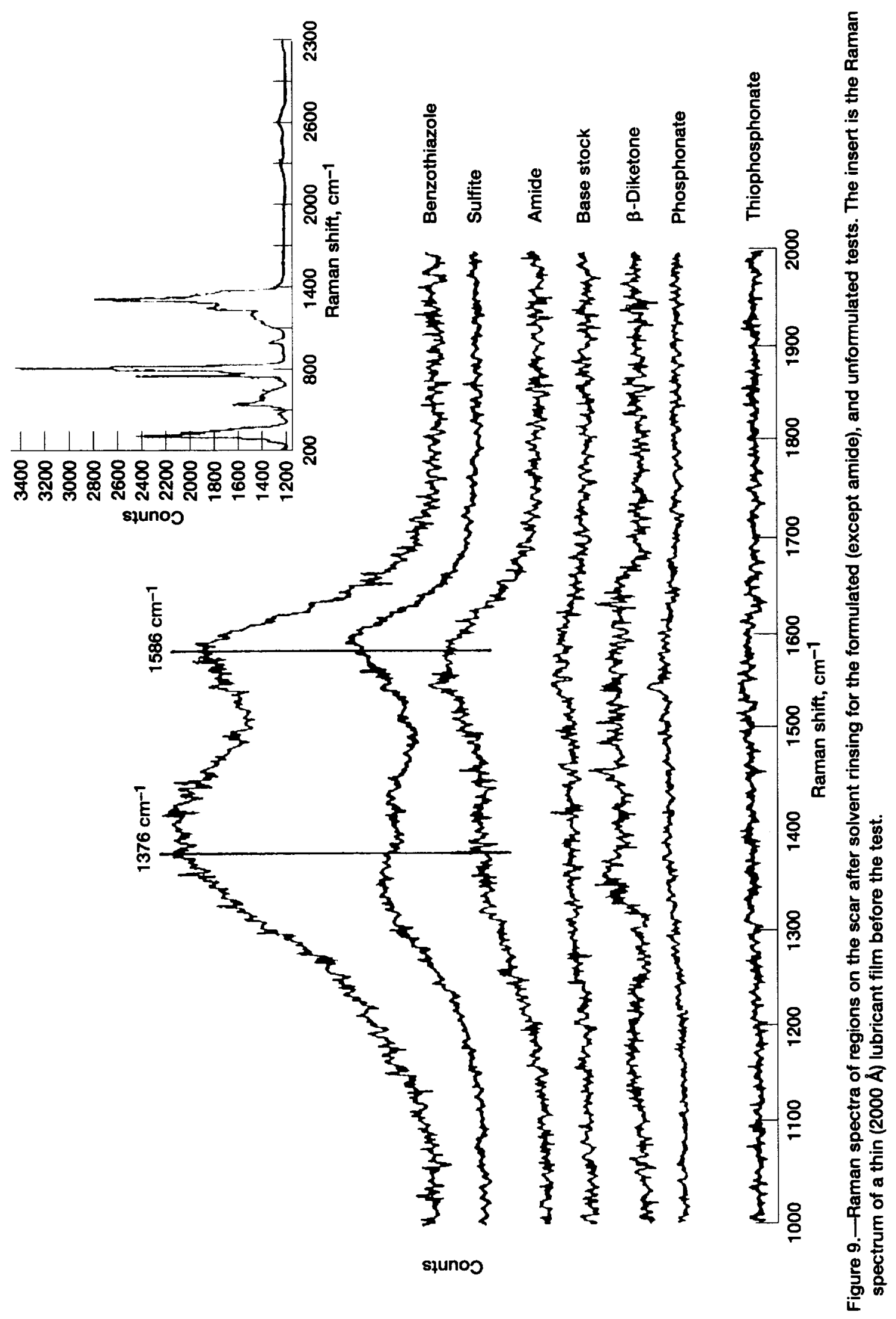


Public reporting burden for this collection of information is estimated to average 1 hour per response, including the time for reviewing instructions, searching existing data sources gathering and maintaining the data needed, and completing and reviewing the collection of information. Send comments regarding this burden estimate or any other aspect of this collection of information, including suggestions for reducing this burden, to Washington Headquarters Services, Directorate for Information Operations and Reports, 1215 Jefferson Davis Highway, Suite 1204, Arlington, VA 22202-4302, and to the Otfice of Management and Budget, Paperwork Reduction Project (0704-0188), Washington, DC 20503.

\begin{tabular}{|l|c|c|}
\hline 1. AGENCY USE ONLY (Leave blank) & $\begin{array}{c}\text { 2. REPORT DATE } \\
\text { December } 1996\end{array}$ & $\begin{array}{r}\text { 3. REPORT TYPE AND DATES COVERED } \\
\text { Technical Memorandum }\end{array}$
\end{tabular}

\section{TITLE AND SUBTITLE}

Evaluation of Boundary-Enhancement Additives for Perfluoropolyethers

6. AUTHOR(S)

Bradley A. Shogrin, William R. Jones, Jr., Pilar Herrera-Fierro, Tzuhn-Yuan Lin, and Hajimu Kawa

National Aeronautics and Space Administration

Lewis Research Center

E-10594

Cleveland, Ohio 44135-3191

9. SPONSORING/MONITORING AGENCY NAME(S) AND ADDRESS(ES)

National Aeronautics and Space Administration

Washington, DC 20546-0001

WU-225-00-00

11. SUPPLEMENTARY NOTES

Prepared for the 1997 Tribology Conference, cosponsored by the Society of Tribologists and Lubrication Engineers and the American Society of Mechanical Engineers, London, United Kingdom, September 8-12, 1997. Bradley A. Shogrin, Case Wesern Reserve University, Cleveland, Ohio 44106; William R. Jones, Jr., NASA Lewis Research Center; Pilar Herrera-Fierro, Ohio Aerospace Institute, 22800 Cedar Point Road, Brook Park, Ohio 44142 (work funded under NASA Contract NAS3-27285); Tzuhn-Yuan Lin and Hajimu Kawa, Exfluor Research Corporation, Round Rock, Texas, 78664. Responsible person, William R. Jones, Jr., organization code 5140, (216) 433-6051.

12a. DISTRIBUTION/AVAILABILITY STATEMENT 12b. DISTRIBUTION CODE

Unclassified - Unlimited

Subject Category 27

This publication is available from the NASA Center for AeroSpace Information, (301) 621-0390.

13. ABSTRACT (Maximum 200 words)

Six additives were synthesized and evaluated as boundary lubrication enhancers for perfluoropolyethers. These additives included a phosphonate, a thiophosphonate, a $B$-diketone, a benzothiazole, an amide and a sulfite. These additives were evaluated in a vacuum four-ball apparatus, at a one weight percent concentration in a perfluoropolyether based on hexafluoropropene oxide. Tests were performed in vacuum $\left(<5.0 \times 10^{-6} \mathrm{Torr}\right)$, at room temperature $\left(\sim 23^{\circ} \mathrm{C}\right)$, at an initial Hertzian stress of $3.5 \mathrm{GPa}(200 \mathrm{~N}$ Load), and a sliding velocity of $28.8 \mathrm{~mm} / \mathrm{sec}(100 \mathrm{rpm})$. Infrared (IR) and Raman spectroscopies were used to analyze the $440 \mathrm{C}$ specimens after testing. Wear rates for each formulation were determined from the slope of wear volume as a function of sliding distance. All additives yielded reductions in mean wear rates of at least 55 percent, with the exception of the benzothiazole which had no effect. Two of the additives, an amide and a sulfite, reduced the mean wear rate by at least 80 percent. IR and Raman analysis indicated the severity of wear can be correlated to the amount of surface fluorinated polymeric acid species $\left(\mathrm{R}_{\mathrm{f}} \mathrm{COOH}\right)$ and amorphous carbon, in and around the wear scar.

14. SUBJECT TERMS

Perfluoropolyethers; Boundary lubrication; Additives
15. NUMBER OF PAGES

22

16. PRICE CODE

$\mathrm{A03}$

\begin{tabular}{|c|c|}
\hline $\begin{array}{l}\text { 17. SECURITY CLASSIFICATION } \\
\text { OF REPORT }\end{array}$ & $\begin{array}{c}\text { 18. SECURTY CLASSIFICATION } \\
\text { OF THIS PAGE } \\
\text { Unclassified }\end{array}$ \\
Unclassified
\end{tabular}

NSN 7540-01-280-5500
19. SECURITY CLASSIFICATION OF ABSTRACT Unclassified
20. LIMITATION OF ABSTRACT

20. LIMITATION OF ABSTAACT


